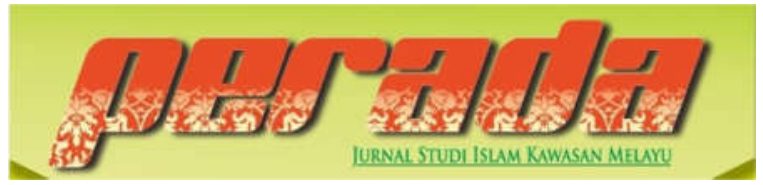

\author{
Perada: Jurnal Studi Islam Kawasan Melayu \\ ISSN 2656-7202 (P) ISSN 2655-6626 (0) \\ Volume 4 Nomor 1, Januari-Juni 2021 \\ DOI: https://doi.org./10.35961/perada.v4i1.283
}

\title{
PRINSIP ACTUATING ISLAM DAN IMPLEMENTASI DALAM MANAJEMEN PENDIDIKAN
}

\author{
Imam Subekti \\ UIN Sultan Thaha Syaifuddin Jambi \\ imamsubekti@yahoo.co.id
}

\begin{abstract}
ABSTRAK
Artikel ini bertujuan untuk mengulas tentang konsep actuating dan prinsipnya dalam Islam pada pola menajemen kepemimpinan, khususnya di sekolah. Fokus artikel ini ialah untuk mengurai tentang konsep dan prinsip-prinsip actuating dalam Islam sebagai pedoman manajemen kepemimpinan yang baik. Beberapa kajian serupa actuating dalam khazanah studi Islam antara lain tabsyir, indzar, dakwah, tarbiyah dan irsyad. Istilah tersebut memang tidak semakna namun menjelaskan bahwa actuating juga penting dalam konsep manajemen kepemimpinan. Sedangkan prinsip-prinsipnya meliputi tadriji, uswah, keseimbangan dan kejelasan. Apabila diimplementasikan maka actuating ini dapat berupa memberikan dan menjelaskan perintah, memberikan petunjuk melaksanakan kegiatan, memberikan kesempatan meningkat-kan pengetahuan, keterampilan atau kecakapan dan keahlian agar lebih efektif dalam melaksanakan berbagai kegiatan organisasi, memberikan kesempatan ikut serta menyumbangkan tenaga dan fikiran untuk memajukan organisasi berdasarkan inisiatif dan kreativitas masing- masing dan memberikan koreksi agar setiap personal melakukan tugastugasnya secara efisien. Maka penting kiranya prinsip actuating dalam Islam ini diterapkan dalam manajemen kepemimpinan di setiap sekolah untuk mendukung manajemen yang baik.
\end{abstract}

This article aims to review the concept of actuating and its principles in Islam on leadership management patterns, especially in schools. The focus of this article is to describe the concepts and principles of actuating in Islam as guidelines for good leadership management. Several studies similar to actuating in the treasures of Islamic studies include tabsyir, indzar, da'wah, tarbiyah and irsyad. The term is not meaningful but explains that actuating is also important in the concept of leadership management. While the principles include tadriji, uswah, balance and clarity. If implemented, this actuating can be in the form of giving and explaining orders, providing instructions for carrying out activities, providing opportunities to increase knowledge, skills or skills and expertise to be more effective in carrying out various organizational activities, providing opportunities to participate in contributing energy and thoughts to advance the organization based on initiative and creativity of each and provide corrections so that each person performs their duties efficiently. So it is important that the actuating principle in Islam is applied in leadership management in every school to support good management.

Kata Kunci: actuating, manajemen kepemimpinan, manajemen pendidikan, 


\section{PENDAHULUAN}

Actuating secara bahasa adalah pengarahan atau dengan kata lain pergerakan pelaksanaan, sedang secara istilah actuating adalah mengarahkan semua karyawan agar mau bekerja sama dan bekerja efektif dalam mencapai tujuan perusahaan atau orgnaisasi. Actuating merupakan bagian dari proses kelompok atau organisasi yang tidak dapat dipisahkan. Adapun istilah yang dapat dikelompokkan ke dalam fungsi ini adalah directing, commanding, leading dan coordinating. ${ }^{1}$

Terry mendefinisikan actuating (penggerakan) sebagai tindakan untuk mengusahakan agar semua anggota kelompok mau bekerjasama dan bekerja secara ikhlas serta bergairah untuk mencapai tujuan sesuai dengan perencanaan dan usaha pengorganisasian. ${ }^{2}$

Dengan kata lain actuating adalah suatu usaha yang dilakukan untuk mencapai tujuan perusahaan dengan berpedoman pada perencanaan (planning) dan usaha pengorganisasian. Pelaksanaan pekerjaan dan pemanfaatan alat-alat bagaimanapun canggihnya atau handalnya, baru dapat dilakukan jika karyawan ikut berperan aktif melaksanakannya. Fungsi pengarahan ini adalah ibarat kunci stater mobil, artinya mobil baru dapat berjalan jika kunci staternya telah melaksanakan fungsinya. Demikian juga proses manajemen baru terlaksana setelah fungsi pengarahan diterapkan. Dalam fungsi ketiga dari manajemen ini ada yang memilah dan memecah ke dalam kegiatan manajemen yang lain.

Kegiatan memerintah, mengkoordinasi, membuat staf paham, mengarahkan, menggerakkan, membuat

1 Jawahir Tanthowi, Unsur-unsur Manajemen Menurut Ajaran Al-Qur'an, Jakarta: Pustaka alHusna, 1983), hal.74

2 Didin Kurniadin dan Imam Machali, Manajemen Pendidikan Konsep \& Prinsip Pengelolaan Pendidikan, (Jogjakarta: Ar Ruzz Media, 2013), hal.287 inovasi, me-ngumpulkan semua sumber daya serta kepemimpinan adalah pekerjaan seorang pemimpin. Banyaknya kegiatan yang harus dilakukan seorang pemimpin inilah yang menyebabkan beberapa pakar manajemen memilah kegiatannya menjadi beberapa langkah.

Dalam proses menggerakkan atau mengarahkan inilah muncul motivasi untuk memberikan pengertian dan kesadaran terhadap dasar dari pekerjaan yang mereka lakukan, sehingga mereka bekerja dengan maksimal untuk mencapai tujuan yang telah direncanakan. Memimpin berarti menciptakan suatu budaya dan nilai bersama, mengkomunikasikan sasaran kepada karyawan melalui organisasi dan memberikan inspirasi agar karyawan berprestasi sebaik-baiknya. ${ }^{3}$

Allah swt menjejelaskan dalam surat An Naml (27) ayat:88

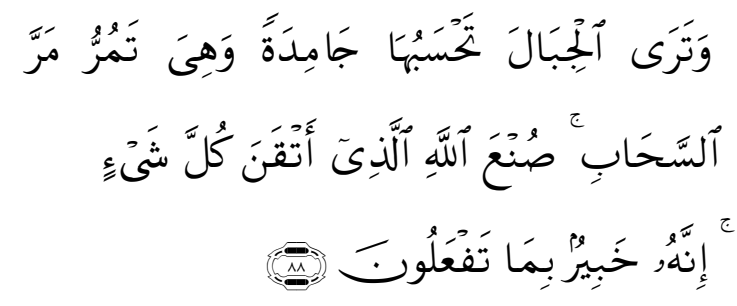

'Dan kamu Lihat gunung-gunung itu, kamu sangka Dia tetap di tempatnya, Padahal ia berjalan sebagai jalannya awan. (Begitulab) perbuatan Allab yang membuat dengan kokoh tiap-tiap sesuatu; Sesunggubnya Allab Maha mengetahui apa yang kamu kerjakan."

Syekh Mahmud Nawari memberikan rumusan tentang actuating dan directing sebagai berikut:

الاتصال بالمرءوسين وارشادهم وترغيبهم للعمل لتحقيق

الأهداف

"Pimpinan selalu memberikan jalanjalan petunjuk atau ilmu pengetabuan serta memperingatkan terhadapanggota atau karyawan guna mencapai tujuan yang sebenarnya."

3 Richard L. Draf, Majemen (Jakarta: Erlangga, 2002), hal.10.

${ }^{4}$ Jawahir Tanthowi, Unsur-unsur Manajemen Menurut Ajaran Al Qur'an, hal.75. 
Menggerakkan sumber daya manusia adalah suatu proses yang dilalui mulai dari perencanaan sumber daya manusia, rekruitmen, pendidikan dan pelatihan sumber daya manusia, serta motivasi yang diberikan kepada sumber daya itu. Sedangkan menggerakkan sumber daya lainnya adalah usaha memaksimalkan peng-gunakan sumber daya yang ada atau menggerakkan elemen-elemen organisasi untuk melakukan semua aktivitas-aktivitas yang telah direncanakan.

Manajemen pendidikan merupakan suatu sistem pengelolaan dan penataan sumber daya pendidikan, seperti tenaga kependidikan, peserta didik, masyarakat, kurikulum, dana, sarana dan prasarana pendidikan, tata laksana, dan lingkungan. Pendapat yang lain manajemen pendidikan dirumuskan sebagai mobilisasi segala sumber daya pendidikan untuk mencapai tujuan pendidikan yang telah ditetapkan. ${ }^{5}$

Konteks masalah manajemen pendidikan adalah manajemen yang diterapkan dalam pengembangan pendidikan. Dalam arti, ia merupakan seni dan ilmu mengelola sumber daya pendidikan Islam untuk mencapai tujuan pendidikan Islam secara efektif dan efisien. Manajemen pendidikan lebih bersifat umum untuk semua aktifitas pendidikan pada umumnya, sedangkan manajemen pendidikan Islam lebih khusus lagi mengarah pada manajemen yang diterapkan dalam pengembangan pendidikan Islam. Pendidikan Islam walaupun mengandung perincian terhadap manajemen pendidikan seperti yang terkandung dalam manajemen pendidikan mutakhir, namun sudah pasti ia mengandung berbagai prinsip umum yang menjadi dasar manajemen pendidikan Islam sehingga ia sejalan dengan kemajuan dan perkembangan yang baik. Fokus manajemen sekolah memfungsikan dan mengoptimalkan kemampuan menyusun

${ }^{5}$ Puji Astutik, Makalah Pemikiran Filosofis Tentang manajemen Pendidikan Islam, 2007, hlm. 2 rencana sekolah dan rencana anggaran, mengelola sekolah berdasarkan rencana sekolah dan rencana anggaran, dan memfungsikan masyarakat untuk berpartisipasi mengelola sekolah. Peranan manajemen sangat ditentukan oleh fungsifungsi manajemen. Fungsi-fungsi inilah yang menjadi inti dari manjemen itu sendiri. Fungsi-fungsi tersebut merupakan proses yang harus dilaksanakan oleh semua pihak yang terlibat dalam sebuah organisasi. Fungsi-fungsi ini pula yang menentukan berhasil atau tidaknya kinerja manajemen.

\section{PRINSIP ACTUATING DALAM ISLAM}

Dalam bahasa Arab, actuating disebut dengan "al-taujib" yang berarti mengarahkan. Dalam Al-Quran Allah SWT telah banyak menyebutkan kata-kata kunci sebagai bentuk pengarahan ataupun menggerakan sumber daya yang ada untuk tercapainya suatu tujuan ataupun keinginan bersama. Beberapa istilah yang berkenaan dalam hal ini adalah sebagai berikut.

1. Tabsyir

Tabsir berarti pemberi kabar gembira, sebagaimana disebutkan dalam Al-Quran Surat Al Baqarah (2) : 213, sebagai berikut :

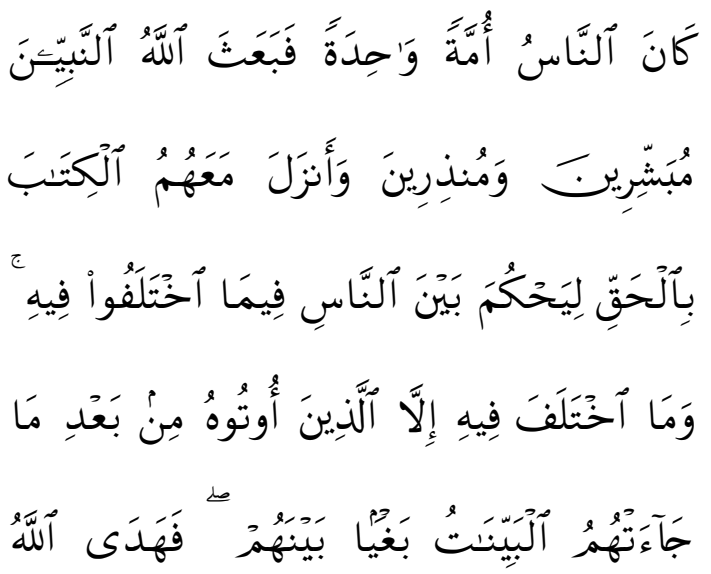




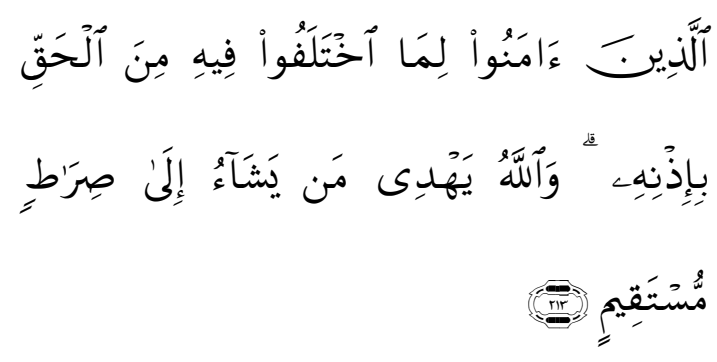

"Manusia itu adalah umat yang satu. (setelah timbul perselisiban), Maka Allah mengutus Para Nabi, sebagai pemberi peringatan, dan Allab menurunkan bersama mereka kitab yang benar, untuk memberi keputusan di antara manusia tentang perkara yang mereka perselisibkan. tidaklah berselisib tentang kitab itu melainkan orang yang telah didatangkan kepada mereka Kitab, Yaitu setelah datang kepada mereka keterangan-keterangan yang nyata, karena dengki antara mereka sendiri. Maka Allab memberi petunjuk orang-orang yang beriman kepada kebenaran tentang hal yang mereka perselisibkann itu dengan kebendak-Nya. dan Allah selalu memberi petunjuk orang yang dikehendaki-Nya kepada jalan yang lurus.,

Dalam ayat ini, Allah SWT mengutus Nabi Muhammad SAW sebagai pembawa kabar gembira dan juga sebagai pemberi peringatan kepada umat manusia. Maka dari sini bisa kita melihat bagaimana seharusnya tugas seorang pemimpin, yaitu dimulai dengan memberikan kabar gembira kepada masyarakatnya. Dari sini Rasulullah sendiri memberikan kabar gembira kepada umatnya akan adanya pahala dan juga balasan atas kebaikan yang dilakukan.

\section{Indzar}

Indzar ini berarti pemberi peringatan. Dalam kitab Tafsir Sya rowi disebutkan bahwa Indzar adalah peringatan kepada orang kafir atas kekufuran meraka dan akan adanya balasan api neraka untuk mereka. Maka langkah kedua yang harus disiapkan oleh seorang pemimpin itu adalah memberi peringatan kepada masyarakatnya. Kata "indzar" juga bisa diartikan memberikan teguran atau punishment kepada bawahan yang tidak disiplin, lalai dalam melaksanakan tugasnya. Dengan punishment yang diberikan kepada seseorang akan menjadi pelajaran bagi orang lain agar tidak melakukan hal serupa dimasa yang akan datang.

Orang yang bertugas memberikan peringatan itu disebut sebagai "mundzir". Dan kegitan seseorang tersebut ingin memberikan peringatan atau indzar kepada orang lain, maka ia terlebih dahulu memiliki ilmu dan juga kemampuan tersebut, sebagaimana dijelaskan dalam AlQuran dalam Surat At Taubah (9): 122

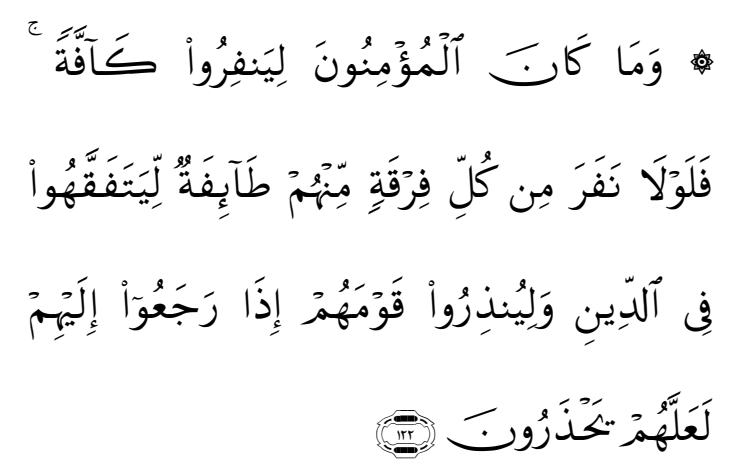

"Tidak sepatutnya bagi mukminin itu pergi semuanya (ke medan perang). mengapa tidak pergi dari tiap-tiap golongan di antara mereka beberapa orang untuk memperdalam pengetabuan mereka tentang agama dan untuk memberi peringatan kepada kaumnya apabila mereka telah kembali kepadanya, supaya mereka itu dapat menjaga dirinya."

Ayat ini memberikan pejelasan kepada kita bahwa, sebagai seorang pemimpin sebelum terjun ke masyarakat atau ke lapangan untuk menyampaikan

${ }^{7}$ QS. At-Thaubah: 122 
peringatan, seharusnya membekali diri terlebih dahulu dengan ilmu dan juga kemampuan- kemampuan lain yang sesuai dengan bidang pekerjannya.

3. Al-Dakwah

Al-Dakwah berarti mengajak ataupun menyeru. Menurut Muhammad Khidr Husain, Dakwah adalah suatu usaha untuk memberikan motivasi kepada orang lain agar mereka melalukan perbuatan baik serta mengikuti jalan petunjuk kebaikan dan melaksanakan amar ma ruf nabi munkar dengan harapan ataupun tujuan untuk mengharapkan kebahagaian dan kesuksesan baik di dunia ataupun di akhirat. ${ }^{8}$ Dalam Al-Quran Surat An-Nahl (16): 125, Allah SWT telah menyebutkan :

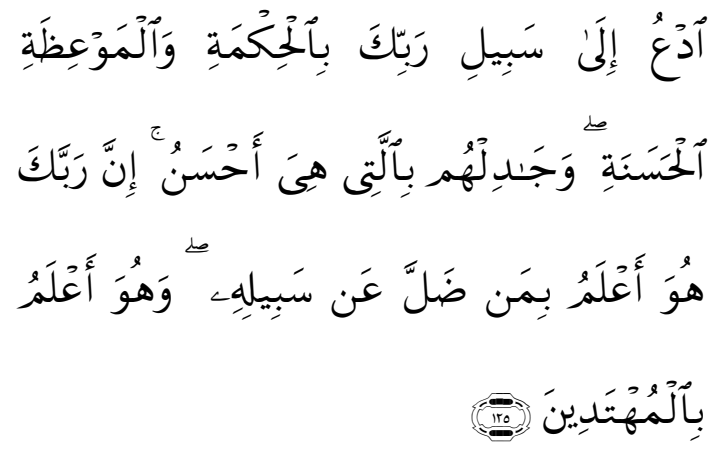

"Serulah (manusia) kepada jalan Tuban-mu dengan bikmah [ialah Perkataan yang tegas dan benar yang dapat membedakan antara yang hak. dengan yang bathil.] dan pelajaran yang baik dan bantablah mereka dengan cara yang baik. Sesunggubnya Tubanmu Dialah yang lebih mengetabui tentang siapa yang tersesat dari jalanNya dan Dialah yang lebih mengetahui orangorang yang mendapat petunjuk.",

4. At-Tarbiyah

8 M. Munir dan Wahyu Ilahi, Manajemen Dakwah (Jakarta: Kencana, 2006), hal. 19

${ }_{9}$ QS. An-Nahal: 125
At-Tarbiyah adalah bentuk masdar dari kata robba-yurobbi-tarbiyatan yang memiliki arti mendidik, mengasuh dan juga memelihara. Muhammad Jamaluddin alQosimi menjelaskan tentang at-Tarbiyah adalah suatu proses menyampaian suatu batasan tentang kesempurnaan yang disampaikan secara bertahap. Dalam AlQuran Surat Al Isra'(17): 24 Allah SWT berfirman:

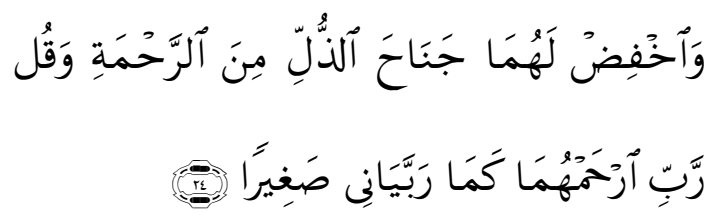

"Dan rendabkanlab dirimu terbadap mereka berdua dengan penub kesayangan dan ucapkanlah: "Wabai Tubanku, kasibilah mereka keduanya, sebagaimana mereka berdua telah mendidik aku waktu kecil." 10

5. Al-Irsyad

Al-Irsyad merupakan pengarahan. Dan pada dasarnya Irsyad adalah salah satu dari sekian banyak bentuk dakwah Islam. Secara substansial filosofis, irsyad berarti menunjukkan kebenaran ajaran dan bimbingan kepada orang lain dalam menjalankannya yang berlangsung dalam suasana tatap muka dengan penuh keakraban. Menurut Abu Al-Farj bin AlJauzi, Al-Irsyad adalah suatu usaha yang dilakukan untuk menyampaikan nasehat kepada orang lain untuk kebaikan ataupun mengarahkan orang lain pada seuatu aktivitas yang positif.

Ada beberapa prinsip dalam pelaksanaan actuating dalam Islam bersumber dari al-Qur'an dan hadis. Beberapa pakar merumuskan prinsip itu sebagai berikut.

\section{Prinsip Tadriji}

Tadriji merupakan suatu kata dari bahasa arab yang memiliki arti berangsur-

${ }^{10}$ QS. Al-Isra : 24 
angsur. Maka hubungan dengan actuating adalah, bahwa dalam melaksanakan tugastugas suatu organisasi, hendaknya kita menggunakan dan mengaplikasikan prinsip bertahap ini. Sehingga tidak akan terjadi penolakan dari objek yang kita sampaikan.

\section{Prinsip Uswah}

Uswah berarti teladan. Dalam proses pengarahan ataupun actuating, sudah semestinya kita juga harus memberikan uswah ataupun teladan yang baik, sehingga objek yang kita tuju akan lebih mudah dalam mengikuti arahan tersebut.

Imam Al-Ghazali menyampaikan dalam kitab Al-Mursyidu Al-Amin bahwa, ketika kita ingin mengajar ataupun menyeru kepada suatu golongan ataupun kelompok yang telah baik ataupun telah memiliki kompetensi yang baik hendaknya dengan cara yang bijaksana, dan jika kepada masyarakat yang masih awam ataupun umum, hendaknya menggunakan metode nasehat atau mau izhah, sedangkan jika dengan masyarakat dari kelompok mu annidin hendaknya dengan cara jidal ataupun debat. ${ }^{11}$

\section{Prinsip Keseimbangan}

Dalam melaksanakan actuating, maka prinsip ke tiga yang harus diterapkan adalah prinsip keseimbangan, artinya adanya reward dan juga punishment, sehingga apa yang kita arahkan tidak hanya didengar tapi betul-betul dilaksanakan, jika dilaksanakan maka akan mendapatkan hadiah ataupun penghargaan dan jika tidak dilaksanakan maka akan mendapakan sanki ataupun hukuman.

\section{Prinsip Kejelasan.}

Prinsip terakhir yang harus diperhatikan dalam pelaksanaan actuating adalah prinsip kejelasan. Maksudnya adalah, bahwa setiap arahan yang kita sampaikan haruslah sesuatu yang jelas dan

11 Imam Abi Hamid Muhammad AlGhozali. Al-Mursyidul Amin, (Darul Kutub AlIslamiyah, 2004), hal. 76 tepat, harus adanya kecermatan sebelum menyampaikan arahan sehingga tidak menimbulkan multitafsir dan perbedaan tanggapan terhadap actuating yang kita laksanakan.

\section{IMPLEMENTASI ACTUATING DA- LAM MANAJEMEN PENDIDIKAN}

Fungsi dari actuating adalah bagian dari proses organisasi atau kelompok yang tidak bisa dipisahkan. Adapun istilah yang sering digunakan dalam fungsi ini ialah directing commanding, leading dan coordinating. ${ }^{12}$

Karena kegiatan actuating
sebagaimana dijelaskan di atas, maka proses ini juga merupakan motivating, untuk memberikan penggerakan dan kesadaran terhadap dasar dari pada pekerjaan yang mereka lakukan, yakni mewujudkan tujuan yang telah ditetapkan, disertai dengan memberi motivasi baru, pengarahan, sehingga mereka bisa menyadari dan timbul kemauan untuk bekerja dengan tekun dan baik. ${ }^{13}$

Al-Qur'an dan hadis sudah menyediakan pedoman dasar yang jelas mengenai actuating dalam manajemen pendidikan Islam yaitu merupakan proses pembimbingan, pengarahan ataupun memberikan peringatan dalam bentuk actuating sebagaimana dalam ayat dan hadits yang telah dibahas dan sajikan secara sederhana di atas. Menurut Hadari Nawawi bimbingan merupakan menjaga, memelihara serta memajukan organisasi oleh setiap personal, baik secara struktural maupun fungsional, supaya seluruh kegiatannya tidak keluar dari usaha mencapai tujuan bersama. ${ }^{14}$ Pada realitanya, kegiatan actuating dapat berupa sebagai berikut : hlm. 71 .

12 Jawahir Tanthowi, Unsur-unsur Manajemen,

13 Muhammad Asrori Ardiansyah, Konsep Manajemen dalam Perspektif Al-Qur'an, (Malang: UIN Malang) hlm. 5

14 Hadari Nawawi, Administrasi Pendidikan, (Jakarta: PT Gunung Agung, 1983), hal. 36. 
1) Memberikan dan menjelaskan perintah

2) Memberikan petunjuk melaksanakan kegiatan

3) Memberikan kesempatan meningkatkan pengetahuan, keterampilan atau kecakapan dan keahlian agar lebih efektif dalam melaksanakan berbagai kegiatan organisasi

4) Memberikan kesempatan ikut serta menyumbangkan tenaga dan fikiran untuk memajukan organisasi berdasarkan inisiatif dan kreativitas masing- masing

5) Memberikan koreksi agar setiap personal melakukan tugas-tugasnya secara efisien.

\section{KESIMPULAN}

Paparan di atas telah menyampaikan pada beberapa kesimpulan. Pertama, actuating adalah serangkaian kegiatan management yang artinya menggerakkan, atau mempengaruhi seluruh komponen organisasi untuk bergerak secara optimal dalam rangka mencapai tujuan yang telah ditetapkan bersama. Aactuating dalam Islam juga telah mendapatkan pembahasan yang cukup serta telah menjadi bagian konsep tersendiri. Beberapa kajian serupa actuating dalam khazanah studi Islam antara lain tabsyir, indzar, dakwah, tarbiyah dan irsyad. Istilah tersebut memang tidak semakna namun menjelaskan bahwa actuating juga penting dalam konsep manajemen kepemimpinan. Sedangkan prinsip-prinsipnya meliputi tadriji, uswah, keseimbangan dan kejelasan. Prinsip tersebut menjadi bagian penting dalam penerapan manajemen kepemimpinan, khususnya di lembaga pendidikan agar lembaga pendidikan semakin maju. []

\section{DAFTAR PUSTAKA}

Tanthowi, Jawahir, Unsur-unsur Manajemen Menurut Ajaran Al-Qur'an, Jakarta: Pustaka al- Husna, 1983.

Kurniadin, Didin dan Imam Machali, Manajemen Pendidikan Konsep \& Prinsip Pengelolaan Pendidikan, Jogjakarta: Ar Ruzz Media, 2013

Richard L. Draf, Majemen, Jakarta: Erlangga, 2002

Astutik, Puji, Pemikiran Filosofis Tentang manajemen Pendidikan Islam, 2007

Munir, M. dan Wahyu Ilahi, Manajemen Dakwah Jakarta: Kencana, 2006

Ghozali, Abi Hamid Muhammad Al-, Al-Mursyidul Amin, Darul Kutub AlIslamiyah, 2004

Ardiansyah, Muhammad Asrori, Konsep Manajemen dalam Perspektif Al-Qur'an, Malang: UIN Malang.

Nawawi, Hadari, Administrasi Pendidikan, Jakarta: PT Gunung Agung, 1983. 